\title{
Physiological and growth responses to water deficit in the bioenergy crop Miscanthus x giganteus
}

\author{
Jennifer Ings, Luis A. J. Mur, Paul R. H. Robson* and Maurice Bosch
}

Institute of Biological, Environmental and Rural Sciences, Aberystwyth University, Aberystwyth, UK

\section{Edited by:}

Yuriko Osakabe, RIKEN Plant Science

Center, Japan

\section{Reviewed by:}

Hazem M. Kalaji, Warsaw University of Life Sciences, Poland

Hannetz Roschzttardtz, University of Wisconsin-Madison, USA

\section{*Correspondence:}

Paul R. H. Robson, Institute of Biological, Environmental and Rural Sciences, Aberystwyth University, Plas Gogerddan, Aberystwyth, SY23 3EB Wales, UK e-mail:ppr@aber.ac.uk
High yielding perennial biomass crops of the species Miscanthus are widely recognized as one of the most promising lignocellulosic feedstocks for the production of bioenergy and bioproducts. Miscanthus is a $\mathrm{C}_{4}$ grass and thus has relatively high water use efficiency. Cultivated Miscanthus comprises primarily of a single clone, Miscanthus x giganteus, a sterile hybrid between $M$. sacchariflorus and $M$. sinensis. $M . \times$ giganteus is high yielding and expresses desirable combinations of many traits present in the two parental species types; however, it responds poorly to low water availability. To identify the physiological basis of the response to water stress in $M . x$ giganteus and to identify potential targets for breeding improvements we characterized the physiological responses to water-deficit stress in a pot experiment. The experiment has provided valuable insights into the temporal aspects of drought-induced responses of $M . \times$ giganteus. Withholding water resulted in marked changes in plant physiology with growth-associated traits among the first affected, the most rapid response being a decline in the rate of stem elongation. A reduction in photosynthetic performance was among the second set of changes observed; indicated by a decrease in stomatal conductance followed by decreases in chlorophyll fluorescence and chlorophyll content. Measures reflecting the plant water status were among the last affected by the drought treatment. Metabolite analysis indicated that proline was a drought stress marker in $M . \times$ giganteus, metabolites in the proline synthesis pathway were more abundant when stomatal conductance decreased and dry weight accumulation ceased. The outcomes of this study in terms of drought-induced physiological changes, accompanied by a proof-of-concept metabolomics investigation, provide a platform for identifying targets for improved drought-tolerance of the Miscanthus bioenergy crop.

Keywords: Miscanthus, drought, water deficit, physiology, metabolite profiling, stress, bioenergy

\section{INTRODUCTION}

Decreasing water availability, as a result of climate change, will lead to prolonged dry periods and hence reduced availability or increased variability in water resources in mid-latitudes and semiarid low latitudes (IPCC, 2007). This combined with an increasing population and increasing societal water demands will lead to water resources being a scarce commodity for agricultural purposes (Rosegrant and Cline, 2003). Drought or water deficit affects crop yield more than any other environmental stress worldwide (Cattivelli etal., 2008), negatively impacting on plant growth, development, survival, and crop productivity, posing a substantial threat to sustainable agriculture (Boyer, 1982).

Biomass from dedicated high yielding bioenergy crops, including tropical $\mathrm{C}_{4}$ grasses from the genus Miscanthus, has been identified as a major source for the production of renewable energy (Carroll and Somerville, 2009; Feltus and Vandenbrink, 2012). Hence, drought induced decreases in yield are of major concern for the development of Miscanthus cultivars that are sustainable and economically viable biomass feedstocks.

Miscanthus is a woody, perennial rhizomatous grass, with a wide indigenous geographical distribution in East-Asia and the genotypes arising from these varying climates differ in their optimal growth condition. While a lot of the research and breeding focus is on the development of Miscanthus hybrids and varieties with improved lignocellulosic biomass yield and conversion efficiencies, the development of drought-tolerant lines will become increasingly important as water resources become more limiting.

Despite water use efficiency of $\mathrm{C}_{4}$ crops often being higher than that of $C_{3}$ crops (Long, 1999; Gowik and Westhoff, 2011), water availability still dictates the maximum yields achievable by a $\mathrm{C}_{4}$ crop such as Miscanthus. The most widely grown and best studied Miscanthus species so far is Miscanthus $\mathrm{x}$ giganteus, a sterile hybrid of M. sacchariflorus and M. sinensis parentage (Hodkinson et al., 2002). M. x giganteus, also referred to as Asian elephant grass, probably has the greatest biomass potential to date with reported dry matter yields after complete plant senescence of 4-32 $\mathrm{t} \mathrm{ha}^{-1}$ year $^{-1}$ in Europe with higher yields in Southern Europe (Lewandowski et al., 2000). Growth trials in the US state of Illinois showed an average yield of $30 \mathrm{tha}^{-1}$ year $^{-1}$ with a significantly higher productivity than maize (Zea mays) and switchgrass (Panicum virgatum) in side-by-side trials (Heaton etal., 2008; Dohleman and Long, 2009). Stabilizing crop performance under drought, which in effect means increasing crop productivity per unit of applied water, will be a main priority for Miscanthus in particular when it is to be grown on marginal land, with little irrigation. 
It has been shown that plants perceive and respond rapidly to even small alterations in water status via physiological, cellular, and molecular events. These responses are determined by the intensity, duration, and rate of progression of the water stress (Chaves et al., 2003). The different physiological changes that can be induced upon drought are well documented. However, the type and timing of physiological responses to drought can vary in different species and between genotypes (Merchant et al., 2007; Centritto et al., 2009; Costa et al., 2012).

While it is clear that unimproved M. x giganteus possesses a range of agronomically desirable traits as a bioenergy feedstock, studies have shown it to be less drought tolerant compared to its parent species, in particular M. sinensis (Clifton-Brown and Lewandowski, 2000) and that drought stress negatively impacts on its yield (Price et al., 2004; Maughan et al., 2012). Despite this, little is known about the physiological traits associated with drought stress in $M . \mathrm{x}$ giganteus.

The main objective of this study was to characterize the physiological responses, and the timing of these responses that $M . \mathrm{x}$ giganteus undergoes when exposed to water stress. This knowledge is important especially considering that bioenergy crops like M. x giganteus are expected to generate high yields on less productive soils with minimal irrigation. Mapping the physiological changes in $M . \mathrm{x}$ giganteus upon drought stress will improve our capacity to evaluate and predict the agronomic performance of this energy crop in response to extreme environments.

Drought elicits substantial changes in plant metabolism as plants accumulate compatible osmolytes inside the plant cell to retain water and maintain positive turgor pressure (Verslues and Juenger, 2011). In addition to relevant phenotype data under water stress we present data showing associated changes in overall metabolite profiles.

The outcomes of this study provide a platform for the identification of potential targets for breeding improvements of the Miscanthus bioenergy crop.

\section{MATERIALS AND METHODS PLANT MATERIAL}

M. x giganteus rhizomes were collected in April 2012 from plants grown as part of a field trial in Aberystwyth, UK. After brief storage at $4^{\circ} \mathrm{C}, 35$ rhizomes with a weight of $20 \pm 5 \mathrm{~g}$ were planted in individual $25 \mathrm{~cm}$ diameter pots containing John Innes No. 3 commercial potting compost. The pots were placed in a glasshouse at $24^{\circ} \mathrm{C}$ with $18 \mathrm{~h}$ of light, and initial growth rate of plants recorded during May-June 2012.

\section{EXPERIMENTAL DESIGN}

The plants were split into five groups of seven replicates with equal standard deviations of height after 2 months of growth. These were placed in a completely randomized design and incubated under the same greenhouse conditions as above. All plants within the five groups were initially watered every 2 days with water being withheld from the water-stressed plants (two groups) from day 12. Selected plants were destructively harvested on day 12 (one group: T0), 24 (two groups: control 1, C1; drought 1, D1), and 32 (two groups: control 2, C2; drought 2, D2). Non-destructive measurements were performed on all plants including those to be removed at destructive harvests on day12, 24, and 32.

\section{PHYSIOLOGICAL MEASUREMENTS}

All measurements were made every 2 days between 22 June-24 July 2012 and were taken from equivalent leaves and from the tallest stem (at beginning of experiment) where multiple stems were present.

Soil moisture content was recorded using a hand-held moisture sensor (SM300 and HH2 moisture meter, Delta-T Devices Ltd., Cambridge, UK), taking the average of three measurements from each pot.

Stomatal conductance was measured between 12:00 and 14:00 h on the youngest leaf with a fully expanded ligule (leaf 0) using an AP4 porometer (Delta-T devices Ltd, Cambridge, UK).

Chlorophyll fluorescence was measured between 10:30 and 12:00 $\mathrm{h}$ on three leaves per plant [leaf $0,-2$ (twoleaves older than leaf 0 ), and 2 (second youngest leaf after leaf 0 )] with a Handy PEA continuous excitation chlorophyll fluorimeter (Hansatech Instruments Ltd., Norfolk, UK). When using the PEA, the attached leaf was dark-adapted with a leaf clip for 30 min before the measurement. During the measurement the PEA sensor unit was held over the clip and the shutter opened. A high intensity LED array on the sensor head provided a maximum light intensity of $3000 \mu \mathrm{mol} \mathrm{m}^{-2} \mathrm{~s}^{-1}$, sufficient to ensure closure of all PSII reaction centers. Maximal PSII photochemical efficiency $F_{\mathrm{v}} / F_{\mathrm{m}}$ (ratio of variable fluorescence to maximum fluorescence) was calculated automatically and recorded. The high data acquisition of $10 \mu \mathrm{s}$ for the first $2 \mathrm{~ms}$ allowed rapid chlorophyll a transients to be determined from the polyphasic curve which were used to calculate additional parameters including performance index (PI) and the quantum yield of electron transport (Oukarroum et al., 2007).

Chlorophyll content was measured on five leaves $(-2,-1,0$, 1, 2; denomination as above) between 10:00 and 12:00 h using a SPAD-502 m (Konica Minolta Optics Inc.). Three readings were taken at quarterly intervals along the leaf and the mean of the values recorded.

Relative water content (RWC) was measured on day 12, 24, and 32 , using samples taken from two leaves per plant (leaf -1 and 1). The RWC was calculated as follows and means were calculated for each plant and treatment:

$$
\operatorname{RWC}(\%)=[(\mathrm{FW}-\mathrm{DW}) /(\mathrm{TW}-\mathrm{DW})] \times 100
$$

(where: $\mathrm{FW}=$ fresh weight, $\mathrm{DW}=$ dry weight, and TW $=$ turgid weight)

Fresh weight was determined at time of cutting, turgid weight after $24 \mathrm{~h}$ in sterile distilled water and dry weight after $72 \mathrm{~h}$ drying in a $60^{\circ} \mathrm{C}$ oven.

Plant water content was evaluated from total above ground biomass measurements taken on day 12, 24, and 32. Fresh weight was recorded at harvest and dry weight was the constant weight achieved after drying in a $60^{\circ} \mathrm{C}$ oven. Water content was calculated on a dry weight basis as follows:

$$
\mathrm{WC}(\mathrm{g} / \mathrm{g})=(\mathrm{FW}-\mathrm{DW}) / \mathrm{DW}
$$




\section{GROWTH MEASUREMENTS}

Stem elongation was measured every 2 days from soil level to the highest fully expanded ligule (leaf 0 ) using a graduated ruler. The rate of elongation was then calculated using these measurements.

Leaf expansion was measured on leaf 0 with leaf length (from the ligule to leaf tip) and width (midway between ligule and tip) measured using a graduated ruler. Leaf area was calculated as described (Clifton-Brown and Lewandowski, 2000):

$$
\text { Area }\left(\mathrm{cm}^{2}\right)=0.74 \times \text { length }(\mathrm{cm}) \times \text { width }(\mathrm{cm})
$$

The rate of expansion was calculated using the leaf area values.

\section{METABOLIC ANALYSIS}

Leaf samples were prepared using ground tissue from leaf 0 and the extraction procedure followed that of Allwood et al. (2006). Metabolites were analyzed using Direct Injection Electrospray Ionization Mass Spectrometry (DI-ESI-MS) on a Micromass LCT mass spectrometer (Micromass/Waters Ltd., UK) in negative ionization mode where metabolites are singly ionized by the loss of $\mathrm{H}^{+}$. The polar extracts were reconstituted in $0.25 \mathrm{~mL} 30 \%[\mathrm{v} / \mathrm{v}]$ methanol : $\mathrm{H}_{2} \mathrm{O}$ and $50 \mu \mathrm{L}$ added to $200 \mu \mathrm{L}$ inserts in $2 \mathrm{~mL}$ (Waters Ltd. UK) and introduced by direct-infusion at a flow rate of $0.05 \mathrm{~mL} \mathrm{~min}^{-1}$ in $30 \%[\mathrm{v} / \mathrm{v}]$ methanol : $\mathrm{H}_{2} \mathrm{O}$ running solvent. Data were acquired over the $\mathrm{m} / \mathrm{z}$ range $100-1400 \mathrm{Th}$ and were imported into MATLAB (The MathWorks Inc., Natwick, MA, USA), binned to unit mass and then normalized to percentage total ion count as described in Johnson et al. (2007).

\section{STATISTICAL ANALYSIS}

Measurements were performed on all remaining plants, minimum seven plants per treatment at each time point, and a mean value calculated for each treatment at each time point. All values are expressed as mean \pm SEM. All analyses were performed using Minitab version 14 (Minitab Inc., Coventry, UK). Statistical differences were estimated from ANOVA tests at the 5\% level ( $p \leq 0.05)$ of significance, for all parameters evaluated. Where ANOVA indicated a significant difference, a pair-wise comparison of means by Fisher's least significant difference (LSD) was carried out. Regression was used to fit lines to the data.

Metabolite data were analyzed using principal components analysis (PCA) following accepted Metabolomics Standard Initiative procedures (Sansone et al., 2007). PCA is an unsupervised method where no a priori knowledge of experimental structure is given. Thus, if there is clustering of either $2 \mathrm{D}$ or projections of PCA from replicate data, this indicates that the original experimental parameters are the sources of maximal variation.

\section{RESULTS}

\section{SOIL MOISTURE CONTENT AND RELATIVE WATER CONTENT}

Figure 1 shows the variation of soil moisture content during the experiment. The final watering of the drought stressed plants was on day 12. From day 16 the volumetric soil moisture content decreased significantly $(p<0.001)$ in water stressed plants when compared with the watered control plants that maintained a constant soil moisture content of $0.3 \mathrm{~m}^{3} \mathrm{~m}^{-3}$. During the course of the drought experiment the soil moisture content readings decreased to $0.05 \mathrm{~m}^{3} \mathrm{~m}^{-3}$, similar levels of soil moisture were observed

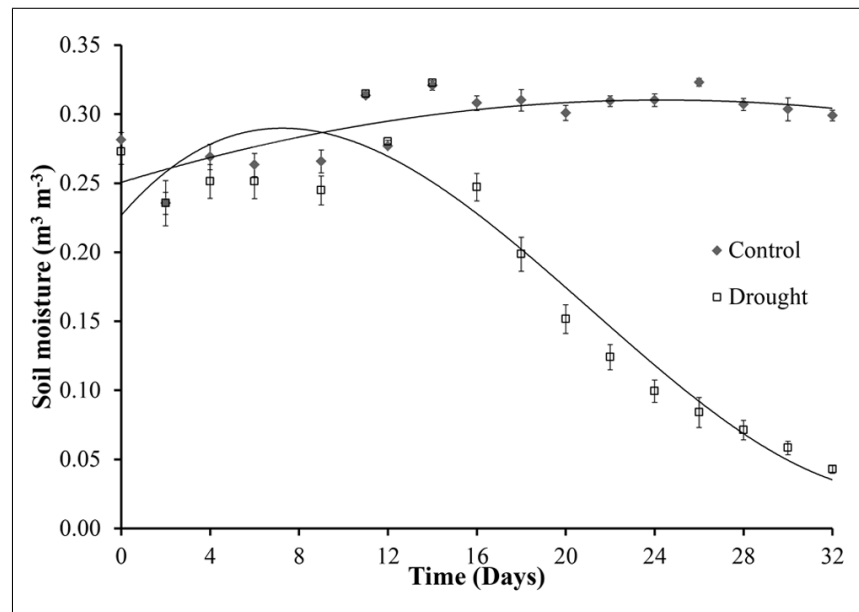

FIGURE 1 | Soil moisture. Soil moisture content was measured every 2 days over a period of 32 days. The last watering of the drought stressed plants was on day 12. The control plants continued to be watered every 2 days for the duration of the experiment. A significant decline in soil moisture occurred on day 16, 4 days after final watering, with a steady decline over the remaining period to levels similar to drought in grassland ecosystems.

during natural drought in a grassland ecosystem (Mikkelsen et al., 2008).

Relative water content measurements determine plant water status at destructive harvests. All plants showed high values of leaf RWC in well-watered conditions at the beginning of the study with an average RWC of $80 \%$ at day 12 (Figure 2A). The effect of the water stress was evident at day 24,12 days after water withdrawal, with a decrease from $80 \%$ leaf RWC in control plants to $<70 \%$ in the water stressed plants. By day 32 there was a significant $(p<0.001)$ treatment difference for leaf RWC between the two groups with the water stressed group declining to $<20 \%$ leaf RWC. As expected, the total above ground biomass moisture content (Figure 2B) followed a very similar pattern to the leaf RWC.

The rate of stem elongation remained fairly constant in the wellwatered plants, with fluctuations in growth rate most likely caused by changing identities of the uppermost leaf with a fully expanded ligule (leaf 0 ). Stem elongation rates in well-watered and waterstressed Miscanthus diverged significantly $(p=0.01)$ at day 20 (Figure 3A) which corresponds to a soil moisture content of below $0.2 \mathrm{~m}^{3} \mathrm{~m}^{-3}$ in the water-stressed plants (Figure 3B). Elongation ceased completely at a soil moisture content of $<0.05 \mathrm{~m}^{3} \mathrm{~m}^{-3}$.

The general effect of mild drought on leaves is a reduction in leaf number (data not shown), rate of expansion and final leaf size. The rate of leaf expansion in well-watered plants was constant throughout the experiment; and decreased in water-stressed plants toward the end of the experiment (Figure 4B). Leaf area in water-stressed plants did not significantly increase after day 26 (Figure 4A) and rate of expansion was significantly different $(p=0.047)$ between the two treatment groups at day 28 (Figure 4B).

To determine the effect of drought on plant harvestable yield, we measured the fresh weight and dry weight of the above ground biomass at three time points (Figure 5). Biomass increased in 


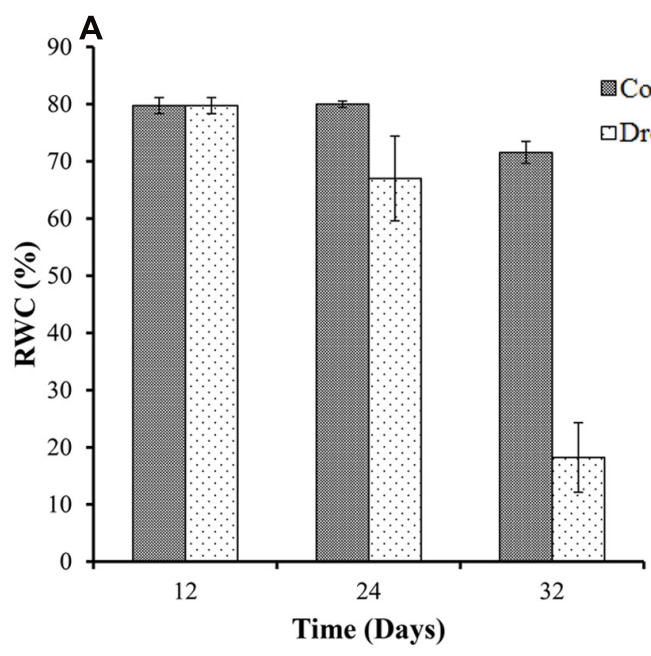

FIGURE 2 | Leaf relative water content and above ground biomass moisture content. The control plants maintained a constant leaf RWC of between 72 and $80 \%$ throughout the duration of the investigation (A). In

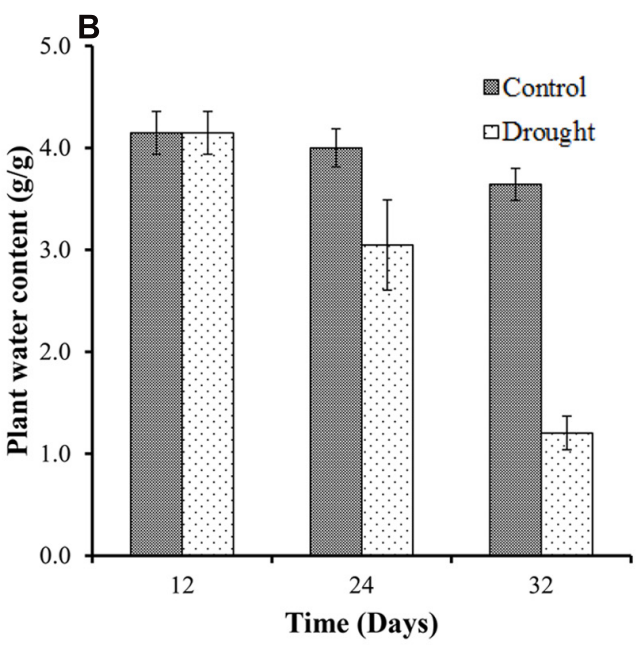

water-stressed plants leaf RWC declined from $80 \%$ at the start of the investigation to $<20 \%$ by day 32 . Total above ground biomass moisture content followed a very similar pattern to the leaf RWC (B)
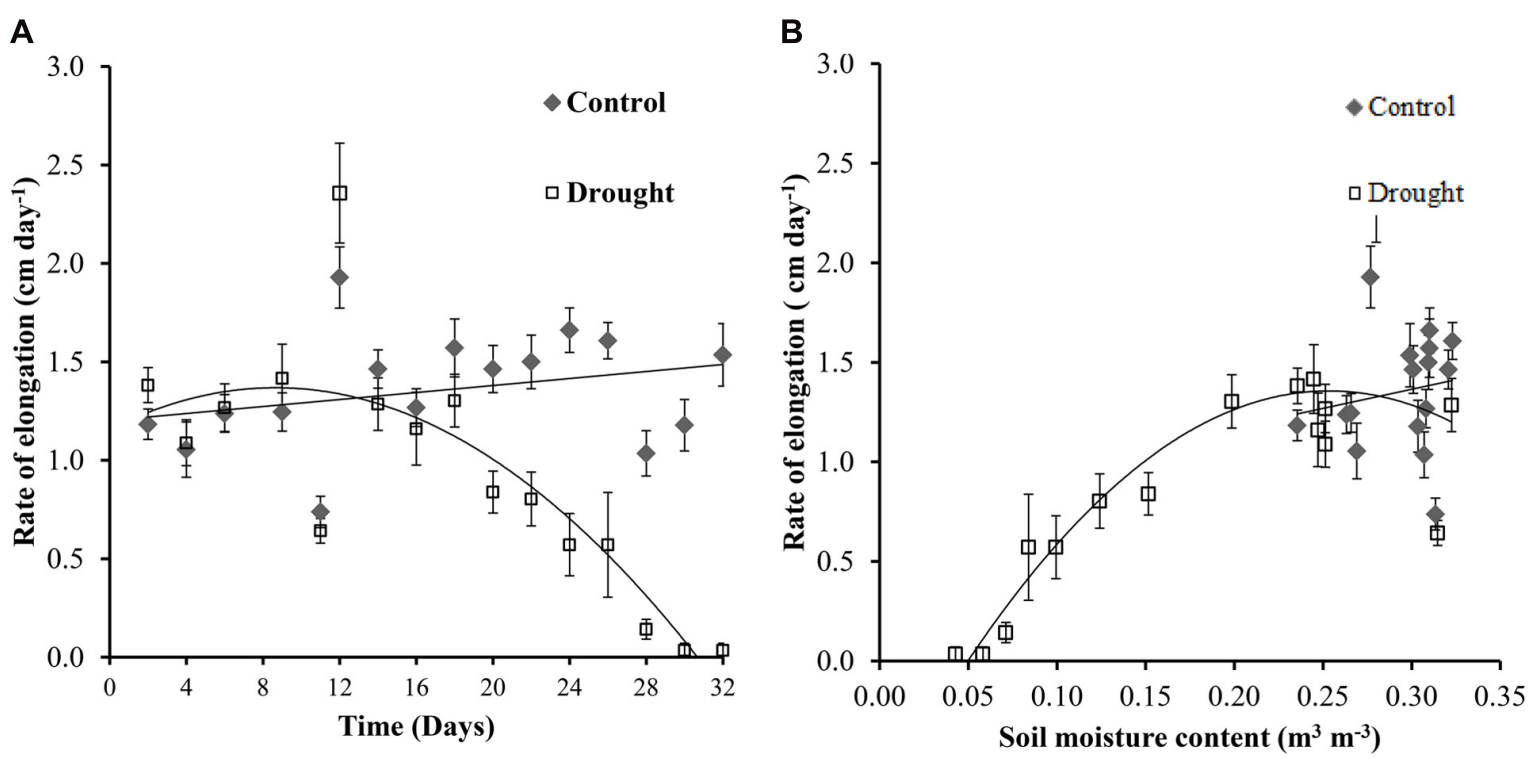

FIGURE 3 | Stem elongation. Control plants showed a fairly constant rate of stem elongation throughout the investigation (A). Water-stressed plants showed a significant decrease in elongation rate from day 20 (A) when the soil moisture decreased to $<0.2 \mathrm{~m}^{3} \mathrm{~m}^{-3}$ (B).

control plants throughout the investigation with a $79 \%$ increase in fresh biomass over 12 days between day 12 and 24 (Figure 5A) and an $84 \%$ increase in dry biomass (Figure 5B) during the same time period. Biomass increased a further 25\% (fresh biomass) and $30 \%$ (dry biomass) during the following 8 days (Figures 5A,B). In water-stressed plants fresh biomass increased $31.5 \%$ over 12 days between day 12 and 24, and decreased by $40 \%$ between day 24 and 32. Biomass dry weight increased in water-stressed plants between day 12 and 24 to a similar extent as in well-watered plants and no further increase in biomass was measured in drought-stressed plants (Figure 5B).

\section{PHOTOSYNTHETIC PRODUCTIVITY}

The chlorophyll content of leaves declined under drought stress (Figure 6). Chlorophyll content was determined for five leaves per plant, with no significant differences between the five leaves. The leaf chlorophyll content was constant in well-watered plants throughout the duration of the experiment (Figure 6). Waterstressed plants maintained chlorophyll levels until day 28 when a uniform significant decline in chlorophyll content occurred across all leaves $(p<0.02)$. At day 32 there was a $42 \%$ decline in leaf chlorophyll content of the water-stressed plants compared to the control well-watered plants. 


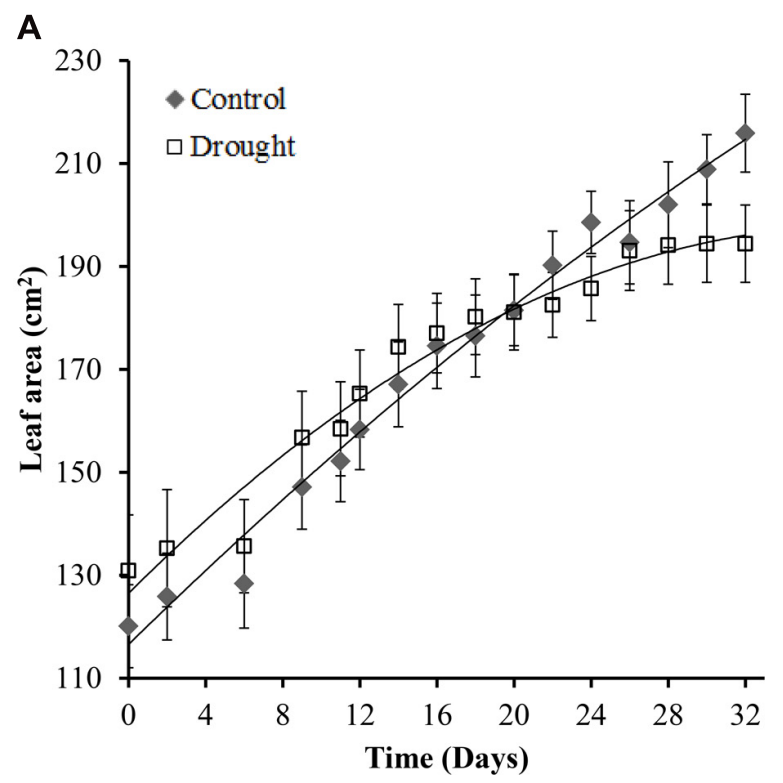

FIGURE 4 | Leaf area and expansion of leaf $\mathbf{0}$. Leaf area showed a linear increase in control plants throughout the experiment while no significant increase after day 26 was observed in water-stressed plants (A). Rate of leaf
B

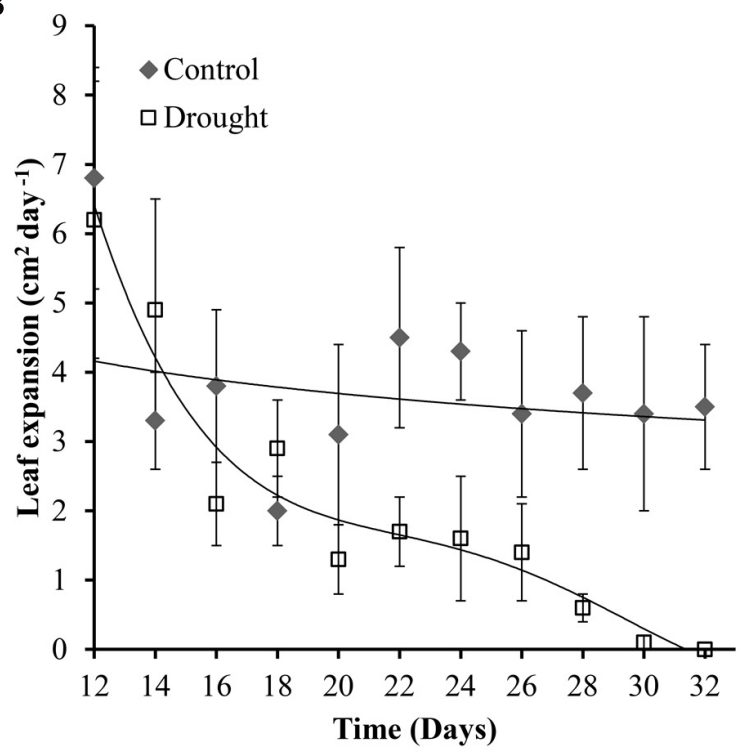

expansion remained constant in control plants and decreased gradually in drought treatment plants (B). The leaf expansion rate became significantly different between the two treatments at day 28 .

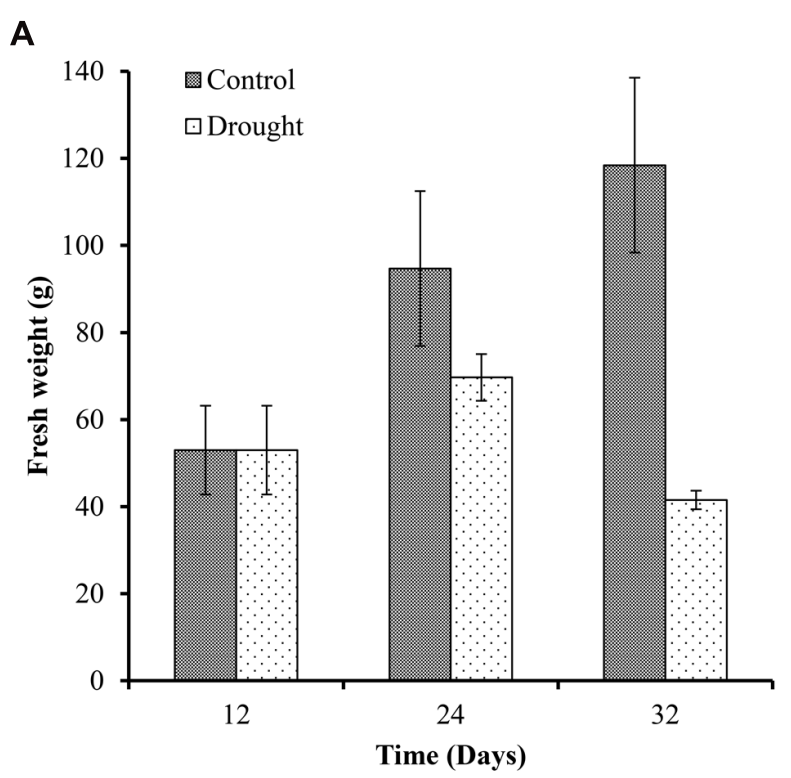

FIGURE $\mathbf{5}$ | Above ground biomass. Fresh (A) and dry weights (B) of the sampled plants were measured at each harvesting point $(n=7)$. Fresh and dry biomass of control plants increased throughout the experiment. Water-stressed plants only showed a small increase in fresh weight
B

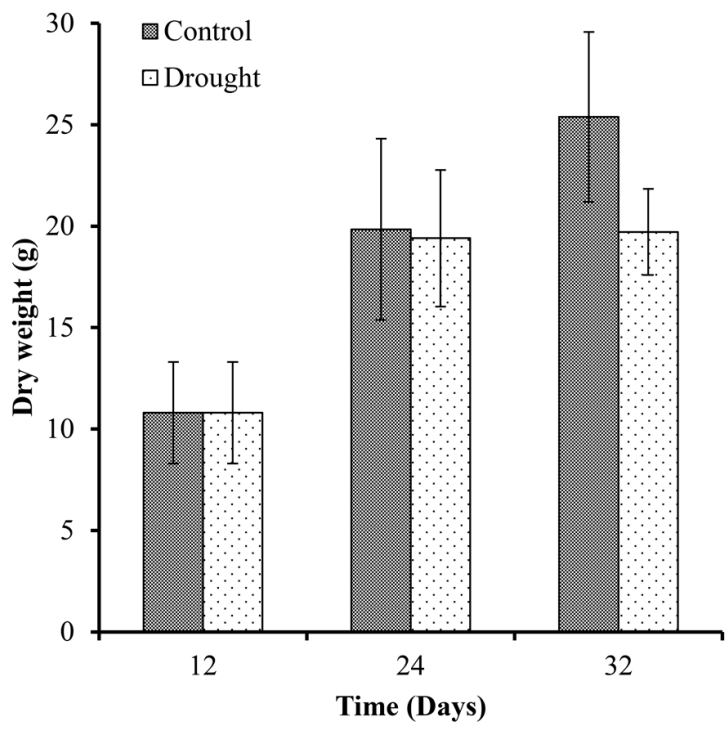

between day 12 and 24 and a significant decrease at day 32. Dry weight accumulation was similar between the two treatments up to day 24 but dry biomass did not increase further in stressed plants between day 24 and 32 .
Chlorophyll fluorescence is a widely used method to research photosynthetic efficiency (Genty et al., 1989; Strasser et al., 1995) and was determined in three leaves per plant, with no significant differences being found between the leaves $(p<0.05)$. Levels of chlorophyll fluorescence were maintained at $0.8 F_{\mathrm{v}} / F_{\mathrm{m}}$ in all leaves under controlled conditions and decreased under drought conditions (Figure 7A). The treatment groups became significantly different at day $28(p<0.04)$ across all different numbered leaves measured. Calculated PI was slightly more sensitive to drought treatment, and treatment groups were significantly different after 26 days (Figure 7B). To test if electron transport prior to the primary plastoquinone $(\mathrm{Qa})$ determined drought induced 


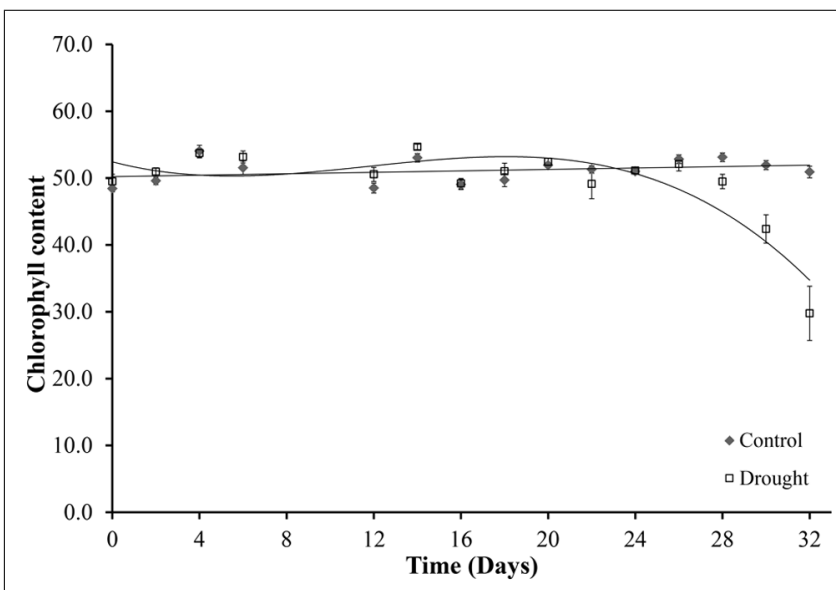

FIGURE 6 | Chlorophyll content. Chlorophyll content was measured in five leaves per plant using a SPAD meter. Leaf 0 is shown because no significant differences were seen between the different leaves. Chlorophyll content was maintained in the well-watered plants for the duration of the experiment and decreased from day 28 under water-stressed conditions. changes in PI the correlation between $\log (\mathrm{PI})$ and $\log (\varphi \mathrm{o})(\varphi \mathrm{o}$ is the quantum yield of electron transport) was tested as described in Oukarroum et al. (2007) and was found to be linear (data not shown).

After cessation of watering, stomatal conductance was unchanged for 10 days (day 22). A significant difference $(p=0.002)$ between the two treatment groups was first observed at day 24. A rapid increase in resistance, corresponding to a decrease in stomatal size, from day 28 then followed until the end of the

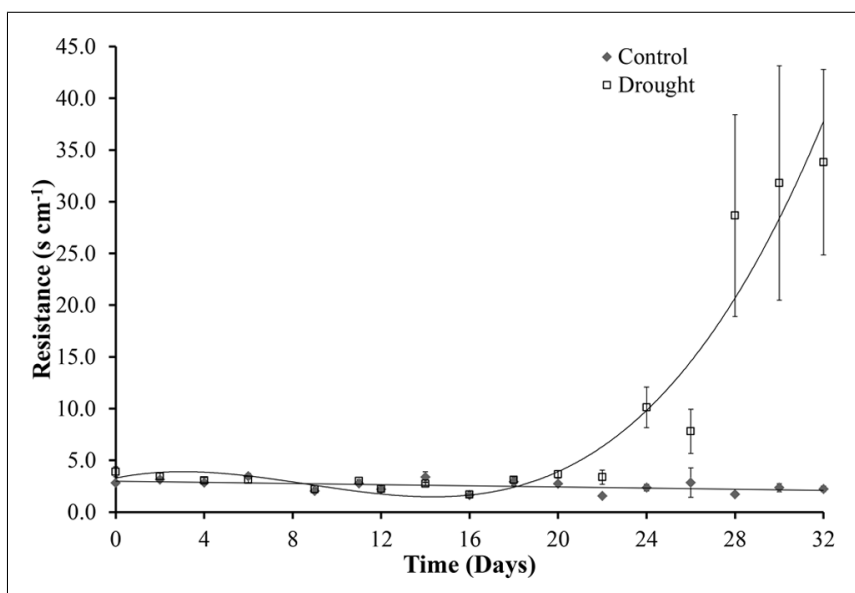

FIGURE 8 | Stomatal conductance. Under controlled well-watered conditions stomatal conductance remained constant throughout the experiment. Water stress caused increased stomatal resistance and therefore a decrease in stomatal conductance, this became significantly different between the two treatments at day 24 .

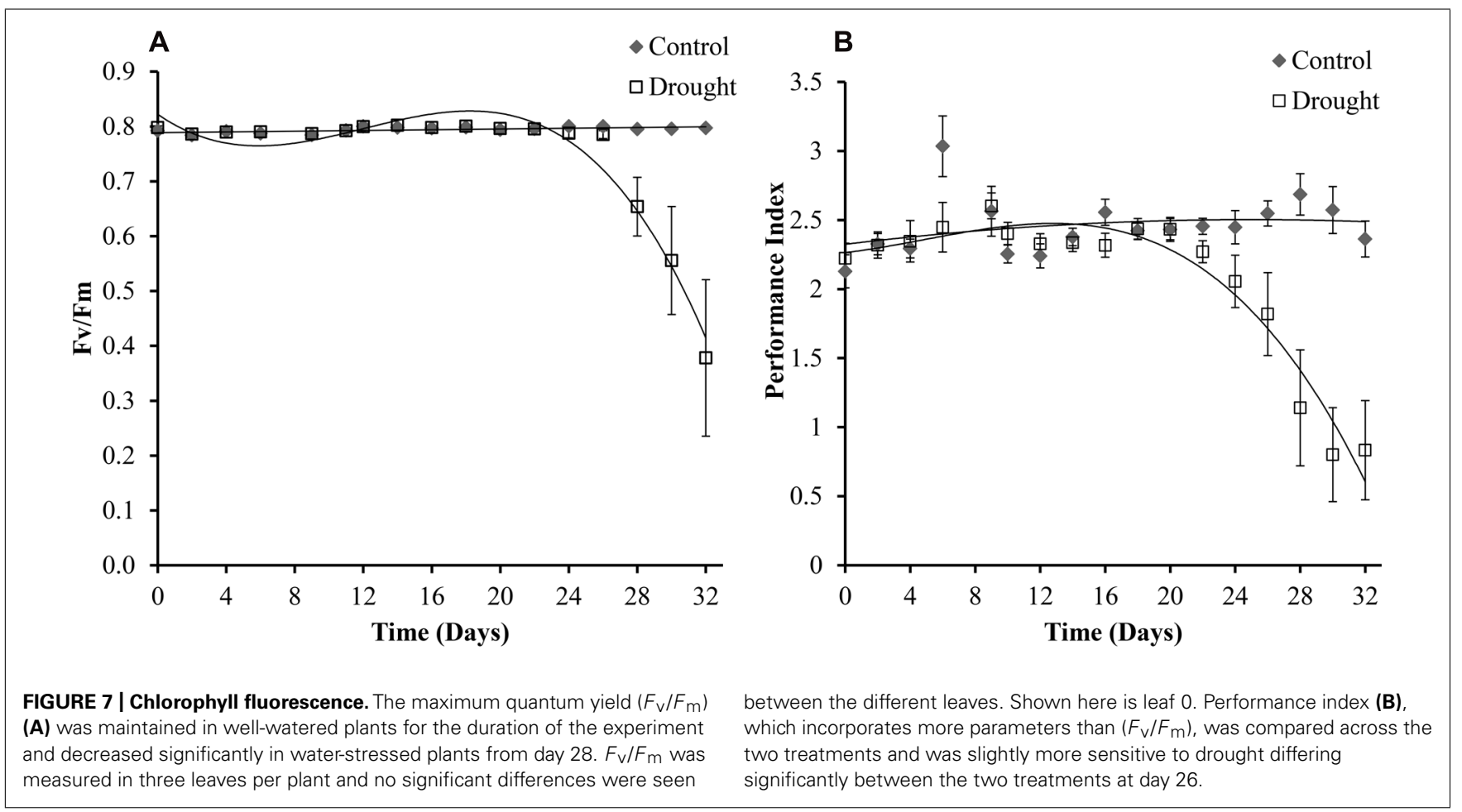




\section{A All metabolites}

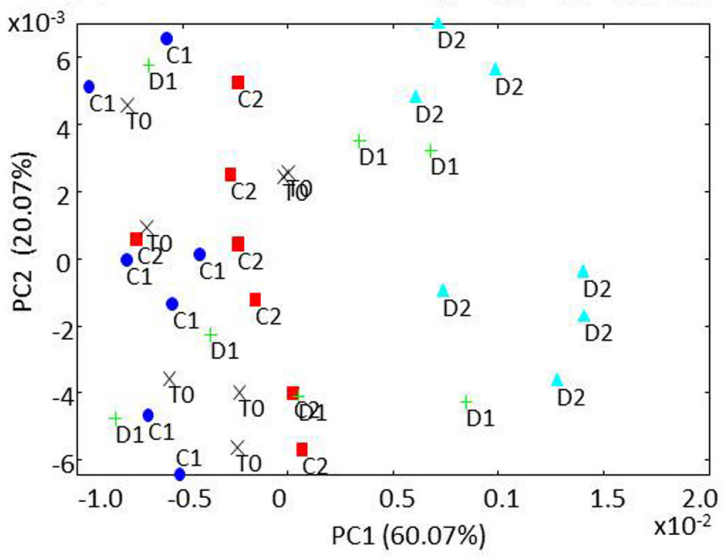

\section{C $m / z$ linked to proline biosynthesis}

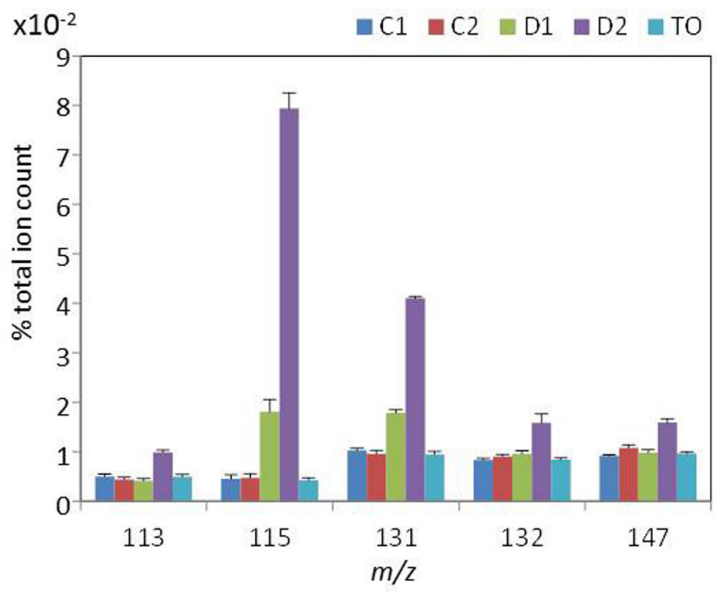

E All metabolites

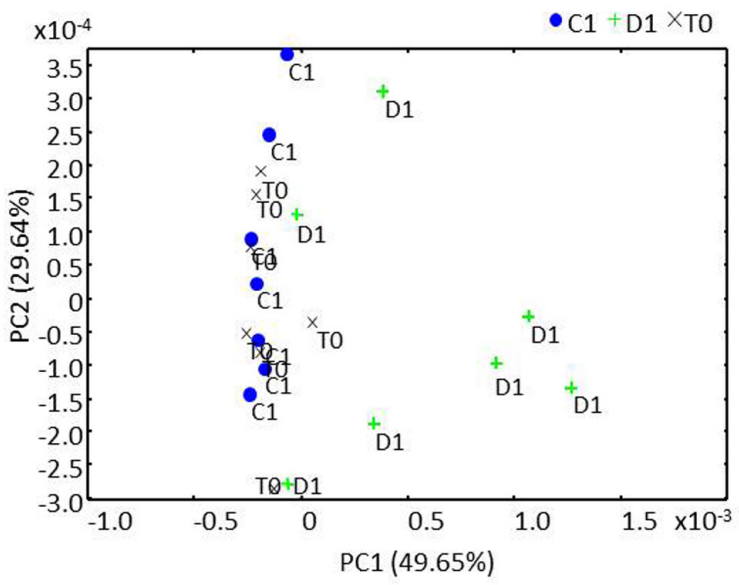

FIGURE 9 | Principal components analysis (PCA) of metabolite profiles from well-watered and water-stressed Miscanthus plants. Polar and non-polar extracts from leaf samples of Miscanthus plants at the start of the experiment day 12 (TO) and from well-watered control plants at day 24 (C1) and day 32 (C2) and also from water-stressed plants at day 24 (D1) and day 32 (D2) were analyzed using direct infusion electrospray ionization mass-spectrometry (DI-ESI-MS). Derived spectra were analyzed by PCA both including C2, D2 (A, D) and excluding C2, D2 (E, F). PCA plots (A) and (D) are

\section{B Major sources of variation}

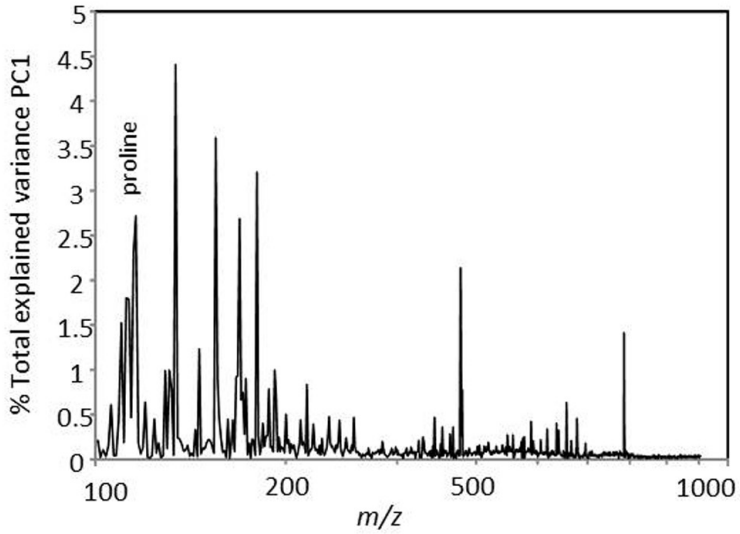

D $m / z$ linked to proline biosynthesis

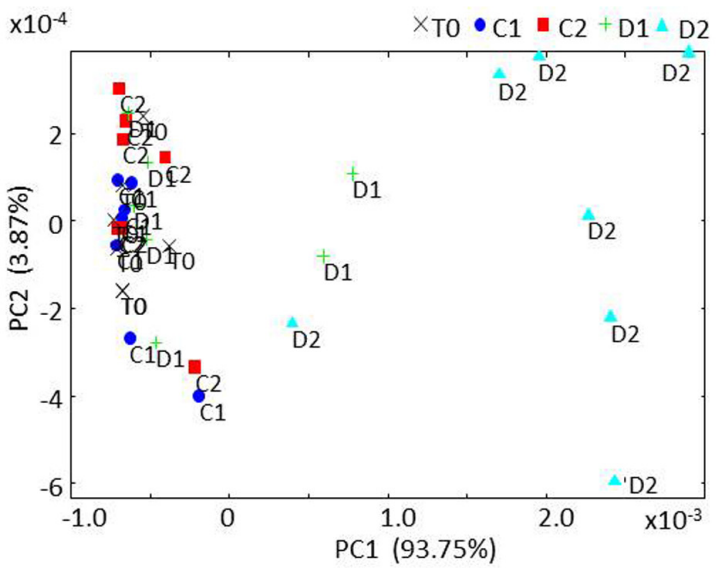

F $m / z$ linked to proline biosynthesis

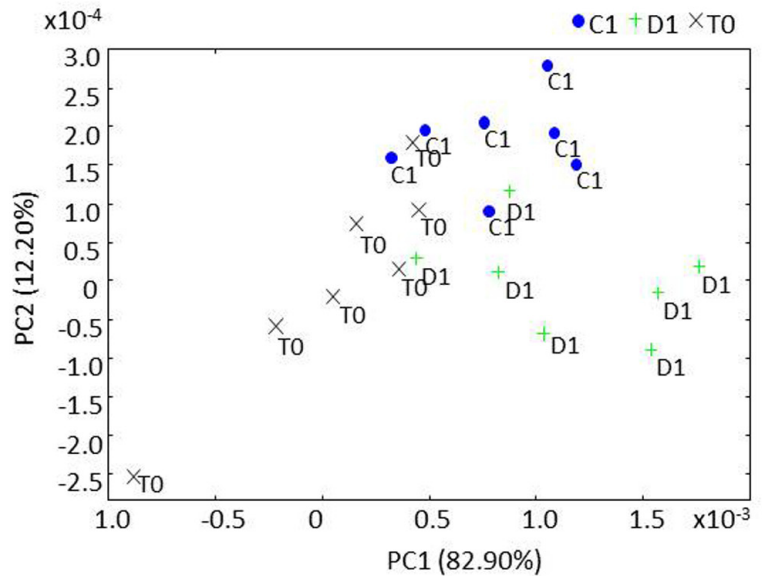

based on data for all metabolites in the spectrum. PCA plots (E) and (F) are based on $\mathrm{m} / \mathrm{z}$ within the spectra which were tentatively linked to metabolites forming the proline biosynthetic pathway namely L-glutamate $(147 \mathrm{~m} / \mathrm{z})$; L-ornithine (132 $\mathrm{m} / \mathrm{z})$; L-glutamate-semi-aldehyde $(131 \mathrm{~m} / \mathrm{z})$,

(S)-pyrroline-5-carboxylate $(113 \mathrm{~m} / \mathrm{z})$, and L-proline $(115 \mathrm{~m} / \mathrm{z})$. (B) The percentage contribution by each $\mathrm{m} / \mathrm{z}$ to the variation explained by PC1 in (A). (C) Percentage to total ion count contributed by each of the five metabolites tentatively associated with proline biosynthesis. 
PCA of derived spectra from all metabolites extracted across three time points and two treatments indicated that metabolites from the D2 group were distinctive to all other samples (Figure 9A). Analysis of the loadings showed that proline ranked amongst the major sources of variation (Figure 9B) contributing $2.78 \%$ to the total variation explained by PC1. Thus, $m / z$ tentatively linked to the proline biosynthetic pathway were extracted from the spectra and all exhibited increased accumulation in the D2 group whilst $m / z 115$ (L-proline) and $m / z 131$ (L-glutamate- $\gamma$-semialdehyde) also increased in the D1 group Figure 9C). Separate analysis of $m / z$ linked to proline biosynthesis by PCA again displayed clear separation of the D2 samples, further suggesting a significant contribution by this pathway to the Miscanthus drought response (Figure 9D). However, other analyses had suggested that Miscanthus plants at day 32 (20 days after cessation of watering) were under severe stress (Figures 6 and 7). Thus, the metabolomic data were re-analyzed with D2 and C2 samples excluded to highlight early responses which could be associated with drought tolerance mechanisms. The resulting PCA suggests that the metabolite profiles for some D1 samples were distinctive from the controls but others were not (Figure 9E). Similarly, when analyzing $\mathrm{m} / \mathrm{z}$ linked to proline biosynthetic metabolites some D1 separation was observed but not for all samples (Figure 9F).

\section{DISCUSSION}

Drought or water deficit is one of the most important factors affecting plant growth, development, survival, and crop productivity, posing a substantial threat to sustainable agriculture. Even the most productive agricultural regions experience short periods of drought and occasional severe drought periods. This has recently become more of an issue due to concerns over the effects of climate change on global agricultural productivity and hence food security and the socio-economic impacts associated with this. Although predictability of precipitation is uncertain, there seems to be a consensus among climate models showing that agricultural areas will be exposed to increasing periods of drought conditions (Falloon and Betts, 2010; Gornall et al., 2010; Trnka et al., 2011). As water resources become more limiting, the development of drought-tolerant crops will become increasingly important.

However, studies that seek to ameliorate the negative impact of drought on agricultural productivity have been mostly focussed upon annually harvested food crops. Many of these studies highlight the particular stages of development that are highly susceptible to drought. For grain crops drought is particularly impactful on crop yield if the water stress coincides with the period of grain filling because the harvest index is largely dependent on assimilate partitioning into grain. As a consequence the mechanisms to improve yield under drought in food crops include for example either avoidance of drought during grain filling such as early crop growth (Fischer et al., 1998; Araus et al., 2002; Farooq et al., 2011), or drought tolerance during grain filling such as stay-green phenotypes (Thomas and Howarth, 2000; Harris et al., 2007). Miscanthus is an undomesticated new crop, with several characteristics that distinguish it from many other crops previously studied in drought research. It is a high yielding crop in which all above ground biomass is harvested annually. This distinguishes it from other biomass crops, such as trees, in which biomass is harvested after several years growth. Therefore Miscanthus represents a mix of annual harvested yield and a perennial growth habit. Because of this unusual combination it is appropriate to consider the particular sensitivities that affect Miscanthus growth and that potentially impact upon yield under drought conditions. We have studied a wide range of physiological responses that may be affected by drought conditions to compare and contrast the responses in Miscanthus with those in other more conventional crops. We have focussed on $M$. x giganteus because much agronomic research has been done on this sterile triploid hybrid species in Europe and the USA, and it is most widely grown for commercial purposes within the Miscanthus genus. Another reason for focussing on $M$. $\mathrm{x}$ giganteus is because drought has been predicted to have a strong negative impact on its performance in terms of biomass yield (Richter et al., 2008; Heaton et al., 2010).

The first observed physiological response in $M . \mathrm{x}$ giganteus under water stress conditions was a decrease in the rate of stem elongation. This stem elongation was significantly different between control and drought from day 20. This is consistent with many crop species in which growth inhibition during drought is primarily due to loss of turgor arising from lack of water availability (Farooq et al., 2009). Inhibition of stem elongation and leaf expansion reduces the demand for metabolites in the plant enabling the synthesis of protective compounds required for osmotic adjustment (Chaves et al., 2003). Leaf and stem elongation have been shown to be sensitive to changes in plant and soil water status in other species including maize (Hsiao et al., 1970; Westgate and Boyer, 1985). Sobrado (1986) reported a strong relationship between leaf expansion rate and predawn leaf turgor in tropical maize varieties; however the relative stem and leaf extension rate was barely associated with grain yield under stress. Miscanthus is cultivated for lignocellulosic biomass and all above ground biomass is harvested and stem traits (elongation and stem number) correlate strongly with yield (Robson et al., 2013). We therefore expected to see significant associations between, in particular, stem elongation rate under stress and yield in Miscanthus. Comparing day 24 and 32 there is little stem elongation and leaf expansion indicating that growth becomes negligible when the soil moisture content drops below $0.1 \mathrm{~m}^{3} \mathrm{~m}^{3}$, reflected by the dry above ground biomass remaining constant over this period.

Measures reflecting the plant water status (leaf RWC, above ground water content and fresh weight) showed a decrease on day 24, becoming significantly different from that of the controls by day 32. The dry weight of drought-treated plants remained the same between day 24 and 32. These results indicate a loss of water from above ground tissues under mild to moderate drought stress but not diminished biomass accumulation. The fact that the mean dry weight between control and treatment were the same on day 24 was somewhat surprising given that a significant reduction in stem elongation was observed in drought treated plants from day 20 onward. However, our data show that photosynthesis is rather resilient in $M . \mathrm{x}$ giganteus under drought stress (discussed below) not showing any significant impact on photosynthetic performance prior to day 24 .

Photosynthesis is one of the key processes of primary metabolism and as such plays a major role in the plants response to low water stress conditions (Chaves et al., 2003). The 
photosynthetic process is affected by water deficits and the impact varies with intensity of the stress. At day 24 changes in photosynthetic measurements were seen with an increase in stomatal resistance. An initial moderate, but significant, increase was observed for 4 days when soil moisture dropped below $0.1 \mathrm{~m}^{3} \mathrm{~m}^{3}$ (day 24 28) before rapid increases in resistance were observed under more severe drought conditions. Stomatal closure, caused by drought induced ABA synthesis, prevents water loss through transpiration. The stomatal conductance to water vapor decreases as the resistance increases. This leads to a decrease in intercellular carbon dioxide concentration and therefore inhibits photosynthesis. It has been previously shown that $M . \mathrm{x}$ giganteus shows little stomatal regulation under mild drought compared to M. sinensis which has shown more effective stomatal control under water limiting conditions (Clifton-Brown and Lewandowski, 2000). In addition to reduced $\mathrm{CO}_{2}$ diffusion through the stomata, water stress also results in reduced $\mathrm{CO}_{2}$ diffusion through the leaf mesophyll (Lawlor and Cornic, 2002). It was therefore expected that changes in chlorophyll content and fluorescence would be seen shortly after the changes to stomatal aperture. However, these two proxy measurements for photosynthetic performance were only affected toward the end of the experiment when drought was more severe, suggesting that $M$. x giganteus employs a drought tolerance strategy, i.e., it continued to function in spite of water stress indicating lack of drought adaptation, compared to the drought avoidance strategy previously seen in $M$. sinensis. $F_{\mathrm{v}} / F_{\mathrm{m}}$ is however not particularly sensitive to changes in photosynthetic capacity under drought (Percival and Sheriffs, 2002), and therefore may not be able to detect the initial decrease in photosynthesis, explaining the delay seen between increased stomatal closure and decrease in photosynthetic performance. The response seen in M. x giganteus is similar to the response seen in maize where dehydration tolerant genotypes were shown to maintain open stomata and active photosynthesis under mild drought conditions (Benesova et al., 2012). Unlike $F_{\mathrm{v}} / F_{\mathrm{m}}$ which utilizes only extreme values of chlorophyll fluorescence, the PI parameter is more comprehensive and incorporates multiple parameters including absorption and trapping of excitation energy, electron transport beyond the primary plastoquinone and dissipation of excitation energy. The PI parameter has been used in several studies of photosynthetic performance (Clark et al., 2000; Hermans et al., 2003; Strauss et al., 2006; Oukarroum et al., 2007). In this study PI was slightly more sensitive than the maximum quantum yield of PSII $\left(F_{\mathrm{v}} / F_{\mathrm{m}}\right)$. The log linear correlation between PI and the quantum yield of electron transport suggests that changes in electron transport beyond Qa determined the changes in PI during drought treatment, a similar result was seen in drought studies of barley cultivars, mung bean (Vigna radiata) and Brassica (Brassica juncea; Misra et al., 2001; Oukarroum et al., 2007).

Biochemical tolerance responses of crops to drought have been linked to changes in the metabolic pathways leading to production of sugars, sugar alcohols, amino acids, and polyamines (reviewed in Seki et al., 2007). Therefore, metabolomics-based approaches are particularly appropriate when investigating plant responses to drought. In this work, we sought to demonstrate the validity of our metabolomics approach to investigate drought in Miscanthus rather than conduct an in depth characterization. However, to demonstrate the biological relevance of our study, we extracted $\mathrm{m} / \mathrm{z}$ corresponding to the proline biosynthetic pathway, one of the largest sources of variation in our experiment, and sought to describe treatment difference based solely on these variables.

Drought induced accumulation of proline, caused by both activation of its biosynthesis and the inactivation of its degeneration, is considered to act as an osmoprotectant, a ROS scavenger, and a molecular chaperone stabilizing the structure of proteins, thereby protecting cells from damage caused by stress (Delauney and Verma, 1993; Hare and Cress, 1997; Szabados and Savoure, 2010). For example, overproduction of proline has been shown to result in increased tolerance to osmotic stress in transgenic plants (Kishor et al., 1995; Zhu et al., 1998; Yamada et al., 2005). Here we have shown that proline biosynthesis is a drought-affected metabolic trait in $M . \mathrm{x}$ giganteus. In our analyses, $\mathrm{m} / \mathrm{z}$ linked to metabolites in the proline pathway allowed responses at day 24 to be distinguished between treatments (D1 and C1), thereby suggesting that biochemically relevant changes linked to drought were being measured in our experiment. It is generally accepted that under conditions of water deprivation or extreme salinity, proline accumulation serves as a defense against osmotic challenge by acting as a compatible solute (Hare and Cress, 1997). The metabolite analysis has shown that at D1, corresponding to mild-moderate drought conditions, the precursor for proline biosynthesis L-glutamatesemi-aldehyde and L-proline itself began to increase. Significantly, L-glutamate-semi-aldehyde and L-proline are respectively the products of two enzymes, pyrroline-5-carboxylate synthetase (P5CS), and pyrroline-5-carboxylate reductase (P5CR) which play major roles in the proline biosynthetic pathway (Delauney and Verma, 1993). Further increases in proline metabolite concentrations within the leaves confirm the importance of proline in the drought stress response of Miscanthus. This could be due to the function of increased proline as a molecular chaperone able to protect protein integrity and enhance the activities of different enzymes (Rajendrakumar et al., 1994). The enhanced rate of proline biosynthesis in chloroplasts can contribute to the stabilization of redox balance and maintenance of cellular homeostasis by dissipating the excess of reducing potential when electron transport is saturated during adverse conditions (Szabados and Savoure, 2010).

With Miscanthus, metabolomics could not only define the mechanisms of drought tolerance but also indicate biochemical markers for maximal biomass yield under drought to be exploited in germplasm selection/ breeding programes. This current work is the first application of metabolomics to investigate drought in Miscanthus. In applying these approaches, we demonstrated the use of appropriate sampling so that multivariate models describing the underlying biochemical changes could be defined. The biochemical changes detected by our metabolite profiling approach were sufficiently pronounced to give treatment specific separation by non-supervised PCA. These experimental data are currently being analyzed in great detail to identify further potential sources of drought tolerance.

The application of progressive drought enabled us to monitor and evaluate the physiological changes in M. $\mathrm{x}$ giganteus triggered over a period of 20 days after cessation of watering. A moderate drought treatment may allow plants to reach a new homeostasis 
with reduced growth (Harb et al., 2010) and a better understanding of this response will allow for the selection of plants that can tolerate limited water availability in temperate climates (Skirycz et al., 2011). M. x giganteus is currently grown over a range of geographies that are expected to experience more erratic climatological conditions including prolonged periods of drought. The progressive decrease in soil moisture content in drought-treated $M$. x giganteus plants allowed us to monitor the associated physiological changes throughout the experiment, summarized in Figure 10, providing valuable information on how $M . \mathrm{x}$ giganteus responds to drought stress. We have shown here that stem elongation is the first measure to be affected. This is therefore a good indicator of early or mild drought stress, with photosynthetic ability being affected under more severe stress. Stomatal conductance was one of the last physiological responses to be affected by drought stress in Miscanthus, this confirms a previous study that suggested $M . \mathrm{x}$ giganteus was poor at controlling stomatal aperture (Clifton-Brown and Lewandowski, 2000). Growth is one of the most drought-sensitive physiological processes with water-stress limiting growth more than any other abiotic stress (Shao et al., 2008). The influence of water deficit and assimilate distribution depends on the stage of growth, with the most rapidly growing organ being most vulnerable to the stress (Nandwal et al., 1992). However the initial decline in elongation growth in drought-stressed Miscanthus was not associated with decreased biomass accumulation but resulted from a redistribution of resource allocation. Since all above ground biomass is harvested in Miscanthus, redistribution of resources among aerial parts of the plant will not affect yield and therefore despite this being the most dramatic and sensitive response it is unlikely to be a useful breeding target for mild drought conditions. However, a shift in assimilate partitioning between structural and non-structural carbohydrates could potentially impact on biomass quality and conversion for bioenergy and bioproducts. It is possible that resources are also redistributed to rhizomatous tissue which would affect yield and it will be interesting to follow resources in drought-stressed plants to determine the relative sensitivities of different resource allocations. Such detailed physiological data provides a platform for the future integration of physiological events with associated drought-induced metabolites and transcripts, enabling the identification of genes and pathways for the improvement of drought tolerance in Miscanthus through implementation in Miscanthus breeding programes and/or genetic engineering approaches.

\section{ACKNOWLEDGMENTS}

The authors would like to acknowledge studentship funding for Jennifer Ings from Aberystwyth University and the Institute of Biological Environmental and Rural Sciences. Paul R. H. Robson

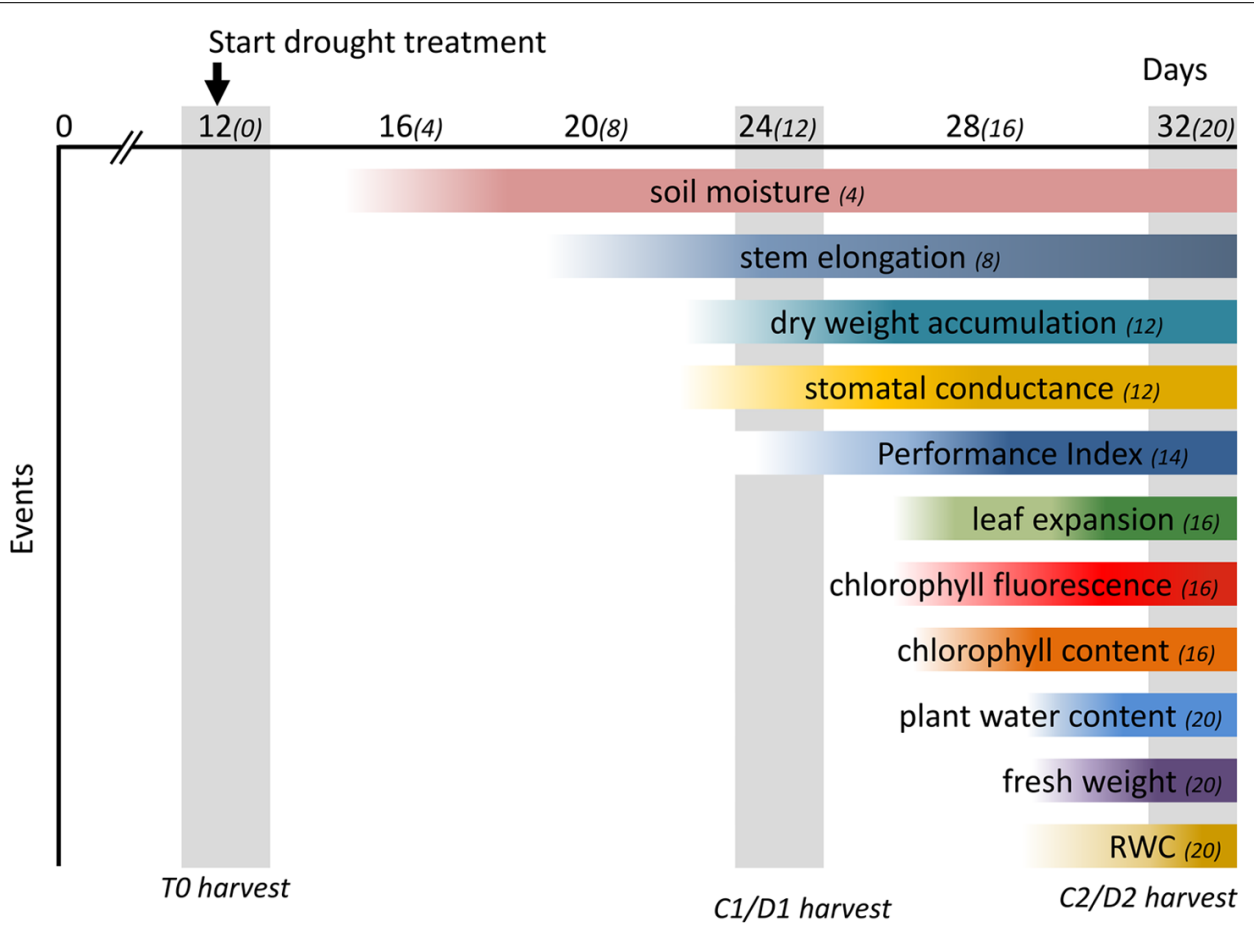

FIGURE 10 | Time-course of physiological changes observed after drought treatment. Soil moisture content decreased significantly 4 days after drought treatment (DADT). The earliest physiological change observed was a decrease in stem elongation (8 DADT) followed by a significant decrease of stomatal conductance and dry weight accumulation (12 DADT). The multi-parametric performance index which incorporates the main photochemical processes was significantly affected at 14 DADT. Leaf expansion rate decreased significantly 16 DADT, although a declining trend could be observed from 8 DADT onward. A significant decline in chlorophyll fluorescence at 16 DADT was accompanied by a decrease of chlorophyll content. Finally, above ground biomass moisture content, fresh weight and RWC all declined significantly at 20 DADT. Numbers in parenthesis indicate days after start of drought treatment. The DADT indicated after each physiological event indicates the day that a significant effect was first observed. Gray vertical bars indicate days for destructive harvests. 
and Maurice Bosch were funded by the Biotechnology and Biological Sciences Research Council (BBSRC) Institute Strategic Programme Grant on Energy Grasses \& Biorefining (BB/J0042/1).

\section{REFERENCES}

Allwood, J. W., Ellis, D. I., Heald, J. K., Goodacre, R., and Mur, L. A. J. (2006). Metabolomic approaches reveal that phosphatidic and phosphatidyl glycerol phospholipids are major discriminatory non-polar metabolites in responses by Brachypodium distachyon to challenge by Magnaporthe grisea. Plant J. 46, 351-368. doi: 10.1111/j.1365-313X.2006.02692.x

Araus, J. L., Slafer, G. A., Reynolds, M. P., and Royo, C. (2002). Plant breeding and drought in C3 cereals: what should we breed for? Ann. Bot. 89, 925-940. doi: 10.1093/aob/mcf049

Benesova, M., Hola, D., Fischer, L., Jedelsky, P. L., Hnilicka, F., Wilhelmova, N., et al. (2012). The physiology and proteomics of drought tolerance in maize: early stomatal closure as a cause of lower tolerance to short-term dehydration? PLoS ONE 7:e38017. doi: 10.1371/journal.pone.0038017

Boyer, J. S. (1982). Plant productivity and environment. Science 218, 443-448. doi: 10.1126/science.218.4571.443

Carroll, A., and Somerville, C. (2009). Cellulosic biofuels. Annu. Rev. Plant Biol. 60 165-182. doi: 10.1146/annurev.arplant.043008.092125

Cattivelli, L., Rizza, F., Badeck, F.-W., Mazzucotelli, E., Mastrangelo, A. M., Francia, E., et al. (2008). Drought tolerance improvement in crop plants: an integrated view from breeding to genomics. Field Crops Res. 105, 1-14. doi:10.1016/j.fcr.2007.07.004

Centritto, M., Lauteri, M., Monteverdi, M. C., and Serraj, R. (2009). Leaf gas exchange, carbon isotope discrimination, and grain yield in contrasting rice genotypes subjected to water deficits during the reproductive stage. J. Exp. Bot. 60, 2325-2339. doi: 10.1093/jxb/erp123

Chaves, M. M., Maroco, J. P., and Pereira, J. S. (2003). Understanding plant responses to drought - from genes to the whole plant. Funct. Plant Biol. 30, 239-264. doi: $10.1071 / \mathrm{fp} 02076$

Clark, A. J., Landolt, W., Bucher, J. B., and Strasser, R. J. (2000). Beech (Fagus sylvatica) response to ozone exposure assessed with a chlorophyll a fluorescence performance index. Environ. Pollut. 109, 501-507. doi: 10.1016/S0269-7491(00) 00053-1

Clifton-Brown, J. C., and Lewandowski, I. (2000). Water use efficiency and biomass partitioning of three different Miscanthus genotypes with limited and unlimited water supply. Ann. Bot. 86, 191-200. doi: 10.1006/anbo.2000.1183

Costa, J. M., Ortuño, M. F., Lopes, C. M., and Chaves, M. M. (2012). Grapevine varieties exhibiting differences in stomatal response to water deficit. Funct. Plant Biol. 39, 179-189. doi: 10.1071/FP11156

Delauney, A. J., and Verma, D. P. S. (1993). Proline biosynthesis and osmoregulation in plants. Plant J. 4, 215-223. doi: 10.1046/j.1365-313X.1993.04020215.x

Dohleman, F. G., and Long, S. P. (2009). More productive than maize in the Midwest: how does Miscanthus do it? Plant Physiol. 150, 2104-2115. doi: $10.1104 /$ pp.109.139162

Falloon, P., and Betts, R. (2010). Climate impacts on European agriculture and water management in the context of adaptation and mitigation - the importance of an integrated approach. Sci. Total Environ. 408, 5667-5687. doi: 10.1016/j.scitotenv.2009.05.002

Farooq, M., Bramley, H., Palta, J. A., and Siddique, K. H. M. (2011). Heat stress in wheat during reproductive and grain-filling phases. Crit. Rev. Plant Sci. 30, 491-507. doi: 10.1080/07352689.2011.615687

Farooq, M., Wahid, A., and Kobayashi, N. (2009). Plant drought stress: effects, mechanisms and management. Agron. Sustain. Dev. 29, 185-212. doi: 10.1051/agro:2008021

Feltus, F. A., and Vandenbrink, J. P. (2012). Bioenergy grass feedstock: current options and prospects for trait improvement using emerging genetic, genomic, and systems biology toolkits. Biotechnol. Biofuels 5, 80. doi: 10.1186/1754-68345-80

Fischer, R. A., Rees, D., Sayre, K. D., Lu, Z.-M., Condon, A. G., and Saavedra, A. L. (1998). Wheat yield progress associated with higher stomatal conductance and photosynthetic rate, and cooler canopies. Crop Sci. 38, 1467-1475. doi: 10.2135/cropsci1998.0011183X003800060011x

Genty, B., Briantais, J. M., and Baker, N. R. (1989). The relationship between the quantum yield of photosynthetic electron-transport and quenching of chlorophyll fluorescence. Biochim. Biophys. Acta 990, 87-92. doi: 10.1016/S03044165(89)80016-9

Gornall, J., Betts, R., Burke, E., Clark, R., Camp, J., Willett, K., et al. (2010). Implications of climate change for agricultural productivity in the early twentyfirst century. Philos. Trans. R. Soc. B Biol. Sci. 365, 2973-2989. doi: 10.1098/ rstb. 2010.0158

Gowik, U., and Westhoff, P. (2011). The path from C3 to C4 photosynthesis. Plant Physiol. 155, 56-63. doi: 10.1104/pp.110.165308

Harb, A., Krishnan, A., Ambavaram, M. M. R., and Pereira, A. (2010). Molecular and physiological analysis of drought stress in arabidopsis reveals early responses leading to acclimation in plant growth. Plant Physiol. 154, 1254-1271. doi: $10.1104 /$ pp. 110.161752

Hare, P. D., and Cress, W. A. (1997). Metabolic implications of stress-induced proline accumulation in plants. Plant Growth Regulat. 21, 79-102. doi: 10.1023/a: 1005703923347

Harris, K., Subudhi, P., Borrell, A., Jordan, D., Rosenow, D., Nguyen, H., et al. (2007). Sorghum stay-green QTL individually reduce post-flowering drought-induced leaf senescence. J. Exp. Bot. 58, 327-338. doi: 10.1093/jxb/erl225

Heaton, E. A., Dohleman, F. G., and Long, S. P. (2008). Meeting US biofuel goals with less land: the potential of Miscanthus. Glob. Change Biol. 14, 2000-2014. doi: 10.1111/j.1365-2486.2008.01662.x

Heaton, E. A., Dohleman, F. G., Miguez, A. F., Juvik, J. A., Lozovaya, V., Widholm, J., et al. (2010). "Chapter 3 - miscanthus: a promising biomass crop," in Advances in Botanical Research, eds K. Jean-Claude and D. Michel (London: Academic Press), 75-137.

Hermans, C., Smeyers, M., Rodriguez, R. M., Eyletters, M., Strasser, R. J., and Delhaye, J.-P. (2003). Quality assessment of urban trees: a comparative study of physiological characterisation, airborne imaging and on site fluorescence monitoring by the OJIP-test. J. Plant Physiol. 160, 81-90. doi: 10.1078/0176-161700917

Hodkinson, T. R., Chase, M. W., Takahashi, C., Leitch, I. J., Bennett, M. D., and Renvoize, S. A. (2002). The use of dna sequencing (ITS and trnL-F), AFLP, and fluorescent in situ hybridization to study allopolyploid Miscanthus (Poaceae). Am. J. Bot. 89, 279-286. doi: 10.3732/ajb.89.2.279

Hsiao, T. C., Acevedo, E., and Henderson, D. W. (1970). Maize leaf elongation: continuous measurements and close dependence of plant water status. Science 168, 590-591. doi: 10.1126/science.168.3931.590

IPCC. (2007). Climate Change 2007: Synthesis Report. Contribution of Working Groups I, II and III to the Fourth Assessment Report of the Intergovernmental Panel on Climate Change [Core Writing Team, R. K. Pachauri, and A. Reisinger (eds)]. (Geneva: IPCC), 104.

Johnson, H., Lloyd, A., Mur, L. J., Smith, A., and Causton, D. (2007). The application of MANOVA to analyse Arabidopsis thaliana metabolomic data from factorially designed experiments. Metabolomics 3, 517-530. doi: 10.1007/s11306-0070065-3

Kishor, P., Hong, Z., Miao, G. H., Hu, C., and Verma, D. (1995). Overexpression of $\Delta$-pyrroline-5-carboxylate synthetase increases proline production and confers osmotolerance in transgenic plants. Plant Physiol. 108, 1387-1394. doi: 10.1104/pp.108.4.1387

Lawlor, D. W., and Cornic, G. (2002). Photosynthetic carbon assimilation and associated metabolism in relation to water deficits in higher plants. Plant Cell Environ. 25, 275-294. doi: 10.1046/j.0016-8025.2001. 00814.x

Lewandowski, I., Clifton-Brown, J. C., Scurlock, J. M. O., and Huisman, W. (2000). Miscanthus: European experience with a novel energy crop. Biomass Bioenergy 19, 209-227. doi: 10.1016/S0961-9534(00)00032-5

Long, S. (1999). "Environmental responses," in C4 Plant Biology, eds R. Sage and R. Monson (San Diego: Academic Press), 215-249.

Maughan, M., Bollero, G., Lee, D. K., Darmody, R., Bonos, S., Cortese, L., et al. (2012). Miscanthus giganteus productivity: the effects of management in different environments. Glob. Change Biol. Bioenergy 4, 253-265. doi: 10.1111/j.17571707.2011.01144.x

Merchant, A., Callister, A., Arndt, S., Tausz, M., and Adams, M. (2007). Contrasting physiological responses of six eucalyptus species to water deficit. Ann. Bot. 100, 1507-1515. doi: 10.1093/aob/mcm 234

Mikkelsen, T. N., Beier, C., Jonasson, S., Holmstrup, M., Schmidt, I. K., Ambus, P., et al. (2008). Experimental design of multifactor climate change experiments with elevated $\mathrm{CO} 2$, warming and drought: the CLIMAITE project. Funct. Ecol. 22, 185-195. doi: 10.1111/j.1365-2435.2007.01362.x 
Misra, A. N., Srivastava, A., and Strasser, R. J. (2001). Utilization of fast chlorophyll a fluorescence technique in assessing the salt/ion sensitivity of mung bean and Brassica seedlings. J. Plant Physiol. 158, 1173-1181. doi: 10.1078/s0176-1617(04)70144-3

Nandwal, A. S., Bharti, S., and Singh, I. (1992). Assimilate partitioning in pigeonpea under 2 levels of drought and during recovery. Biol. Plant. 34, 267-273. doi: $10.1007 / \mathrm{bf} 02925881$

Oukarroum, A., Madidi, S. E., Schansker, G., and Strasser, R. J. (2007). Probing the responses of barley cultivars (Hordeum vulgare L.) by chlorophyll a fluorescence OLKJIP under drought stress and re-watering. Environ. Exp. Bot. 60, 438-446. doi: 10.1016/j.envexpbot.2007.01.002

Percival, G. C., and Sheriffs, C. N. (2002). Identification of drought-tolerant woody perennials using chlorophyll fluorescence. J. Arboric. 28, 215-223.

Price, L., Bullard, M., Lyons, H., Anthony, S., and Nixon, P. (2004). Identifying the yield potential of Miscanthus x giganteus: an assessment of the spatial and temporal variability of $M . \mathrm{x}$ giganteus biomass productivity across England and Wales. Biomass Bioenergy 26, 3-13. doi: 10.1016/s0961-9534(03)00062-x

Rajendrakumar, C. S. V., Reddy, B. V. B., and Reddy, A. R. (1994). Prolineprotein interactions - protection of structural and functional integrity of $\mathrm{m}(4)$ lactate-dehydrogenase. Biochem. Biophys. Res. Commun. 201, 957-963. doi 10.1006/bbrc.1994.1795

Richter, G. M., Riche, A. B., Dailey, A. G., Gezan, S. A., and Powlson, D. S. (2008). Is UK biofuel supply from Miscanthus water-limited? Soil Use Manage. 24, 235-245. doi: 10.1111/j.1475-2743.2008.00156.x

Robson, P., Jensen, E., Hawkins, S., White, S. R., Kenobi, K., Clifton-Brown, J., et al. (2013). Accelerating the domestication of a bioenergy crop: identifying and modelling morphological targets for sustainable yield increase in Miscanthus. $J$. Exp. Bot. 64, 4143-4155. doi: 10.1093/jxb/ert225

Rosegrant, M. W., and Cline, S. A. (2003). Global food security: challenges and policies. Science 302, 1917-1919. doi: 10.1126/science.1092958

Sansone, S.-A., Fan, T., Goodacre, R., Griffin, J. L., Hardy, N. W., Kaddurah-Daouk, R., et al. (2007). The metabolomics standards initiative. Nat. Biotech. 25, 846-848. doi: $10.1038 /$ nbt0807-846b

Seki, M., Umezawa, T., Urano, K., and Shinozaki, K. (2007). Regulatory metabolic networks in drought stress responses. Curr. Opin. Plant Biol 10, 296-302. doi: 10.1016/j.pbi.2007.04.014

Shao, H. B., Chu, L. Y., Jaleel, C. A., and Zhao, C. X. (2008). Water-deficit stressinduced anatomical changes in higher plants. C. R. Biol. 331, 215-225. doi: 10.1016/j.crvi.2008.01.002

Skirycz, A., Vandenbroucke, K., Clauw, P., Maleux, K., De Meyer, B., Dhondt, S., etal. (2011). Survival and growth of Arabidopsis plants given limited water are not equal. Nat. Biotechnol. 29, 212-214. doi: 10.1038/ nbt. 1800

Sobrado, M. A. (1986). Tissue water relations and leaf growth of tropical corn cultivars under water deficits. Plant Cell Environ. 9, 451-457. doi: 10.1111/j.13653040.1986.tb01760.x
Strasser, R. J., Srivastava, A., and Govindjee, G. (1995). Polyphasic chlorophyllalpha fluorescence transient in plants and cyanobacteria. Photochem. Photobiol. 61, 32-42. doi: 10.1111/j.1751-1097.1995.tb09240.x

Strauss, A. J., Krüger, G. H. J., Strasser, R. J., and Heerden, P. D. R. V. (2006) Ranking of dark chilling tolerance in soybean genotypes probed by the chlorophyll a fluorescence transient O-J-I-P. Environ. Exp. Bot. 56, 147-157. doi: 10.1016/j.envexpbot.2005.01.011

Szabados, L., and Savoure, A. (2010). Proline: a multifunctional amino acid. Trends Plant Sci. 15, 89-97. doi: 10.1016/j.tplants.2009.11.009

Thomas, H., and Howarth, C. J. (2000). Five ways to stay green. J. Exp. Bot. 51, 329-337. doi: 10.1093/jexbot/51.suppl_1.329

Trnka, M., Olesen, J. E., Kersebaum, K. C., Skjelvåg, A. O., Eitzinger, J., Seguin, B., et al. (2011). Agroclimatic conditions in Europe under climate change. Glob. Change Biol. 17, 2298-2318. doi: 10.1111/j.1365-2486.2011.02396.x

Verslues, P. E., and Juenger, T. E. (2011). Drought, metabolites, and Arabidopsis natural variation: a promising combination for understanding adaptation to water-limited environments. Curr. Opin. Plant Biol. 14, 240-245. doi: 10.1016/j.pbi.2011.04.006

Westgate, M. E., and Boyer, J. S. (1985). Osmotic adjustment and the inhibition of leaf, root, stem and silk growth at low water potentials in maize. Planta 164, 540-549. doi: 10.1007/bf00395973

Yamada, M., Morishita, H., Urano, K., Shiozaki, N., Yamaguchi-Shinozaki, K., Shinozaki, K., et al. (2005). Effects of free proline accumulation in petunias under drought stress. J. Exp. Bot. 56, 1975-1981. doi: 10.1093/jxb/eri195

Zhu, B., Su, J., Chang, M., Verma, D. P. S., Fan, Y.-L., and Wu, R. (1998). Overexpression of a $\Delta 1$-pyrroline-5-carboxylate synthetase gene and analysis of tolerance to water- and salt-stress in transgenic rice. Plant Sci. 139, 41-48. doi: 10.1016/S0168-9452(98)00175-7

Conflict of Interest Statement: The authors declare that the research was conducted in the absence of any commercial or financial relationships that could be construed as a potential conflict of interest.

Received: 14 August 2013; accepted: 30 October 2013; published online: 25 November 2013.

Citation: Ings J, Mur LAJ, Robson PRH and Bosch M (2013) Physiological and growth responses to water deficit in the bioenergy crop Miscanthus $x$ giganteus. Front. Plant Sci. 4:468. doi: 10.3389/fpls.2013.00468

This article was submitted to Plant Physiology, a section of the journal Frontiers in Plant Science.

Copyright (c) 2013 Ings, Mur, Robson and Bosch. This is an open-access article distributed under the terms of the Creative Commons Attribution License (CC BY). The use, distribution or reproduction in other forums is permitted, provided the original author(s) or licensor are credited and that the original publication in this journal is cited, in accordance with accepted academic practice. No use, distribution or reproduction is permitted which does not comply with these terms. 